\title{
Current Status and Future Prospects of Magnetic Resonance Imaging in Perinatal Medicine
}

\author{
${ }^{1}$ Kriengkrai lemsawatdikul, ${ }^{2}$ Preeyacha Pacharn, ${ }^{3}$ Suparat Jaingam, ${ }^{4}$ Katika Nawapun, ${ }^{5}$ Nisarat Phithakwatchara \\ ${ }^{6}$ Tuangsit Wataganara
}

\begin{abstract}
Fetal magnetic resonance imaging (MRI) has become an important adjuvant to high-quality ultrasound once fetal structural anomaly is identified. There are recently developed advanced techniques such as provision of volumetric data, spectroscopy, and functional MRI. Changes in local susceptibility caused by blood breakdown products, echo-planar imaging (EPI) sequences [i.e., diffusion-weighted imaging (DWI) and apparent diffusion coefficient (ADC)] are especially sensitive to hemorrhage and edema. These novel sequences are particularly useful for assessment of fetal ischemic and hemorrhagic brain lesions. Prenatal MRI has been increasingly adopted in assessment and follow-up after in utero surgeries of twin-twin transfusion syndrome, congenital diaphragmatic hernia, lower urinary tract obstruction, and myelomeningocele. Development of guidelines to better define the role of fetal MRI in relation to prenatal diagnostic ultrasound can reduce the variation of sequence protocols, magnetic field intensity, as well as the use of gadolinium performed in different centers. Novel sequences may be used for research purposes, but safety concerns of obstetric MRI cannot be overlooked. The current utilities and future prospects of MRI in perinatal medicine are updated in this article.
\end{abstract}

Keywords: Fetal magnetic resonance imaging, Fetal neuroimaging, Fetal therapy, Functional magnetic resonance imaging, Placental perfusion.

How to cite this article: lemsawatdikul K, Pacharn $P$, Jaingam $S$, Nawapun K, Phithakwatchara N, Wataganara T. Current Status and Future Prospects of Magnetic Resonance Imaging in Perinatal Medicine. Donald School J Ultrasound Obstet Gynecol 2018;12(2):89-93

Source of support: Nil

Conflict of interest: None

\section{INTRODUCTION}

Fetal MRI has become an important adjuvant as confirmatory and acquisition of additional information, to high-quality ultrasound once fetal structural anomaly is

\footnotetext{
${ }^{1,4}$ Assistant Professor, ${ }^{2,5,6}$ Associate Professor, ${ }^{3}$ Research Assistant

1,2Department of Radiology, Faculty of Medicine, Siriraj Hospital Bangkoknoi, Bangkok, Thailand

${ }^{3-6}$ Department of Obstetrics and Gynecology, Faculty of Medicine, Siriraj Hospital, Bangkoknoi, Bangkok, Thailand

Corresponding Author: Tuangsit Wataganara, Associate Professor, Department of Obstetrics and Gynecology, Faculty of Medicine, Siriraj Hospital, Bangkoknoi, Bangkok, Thailand Phone: +0116624197000, e-mail: twataganara@yahoo.com
}

identified. ${ }^{1,2}$ It is not recommended to use MRI as a primary screening tool in prenatal care. Basic advantages of MRI are: (1) Provision of images in any plane or fetal position; (2) providing a large field of view; and (3) excellent soft tissue contrast resolution, even in the presence of limited liquor volume, overlying bone, or obesity. ${ }^{3}$ Still, motion artifact (fetal or maternal) limits the sequences available.

Echo-planar imaging techniques have become increasingly important in cases with difficult characterization of certain fetal tissues, i.e., skeletal dysplasias and pathologies. ${ }^{4}$ The recently developed advanced techniques, such as (1) Provision of volumetric data; (2) spectroscopy; and (3) functional images have expanded the lexicon to include such terms as magnetic resonance angiography, magnetic resonance spectrography, and functional MRI. Although there is no evidence that MRI produces long-term harmful effects regarding radiofrequency fields and the loud acoustic environment, there is still lack of consensus regarding its utility and safety. ${ }^{5}$ The International Society of Ultrasound in Obstetrics and Gynecology recently suggested clinical indications and limitations of fetal MRI. ${ }^{6}$ In this Editorial, we are aiming to update the current utilities and future prospects of MRI in perinatal medicine.

\section{Fetal Neurological MRI}

Ventriculomegaly detected from prenatal ultrasound may be the most common indication for fetal MRI. Neuroimaging MR study attempts to identify morphological and functional changes in the fetal brain during its maturational course. In utero MR assessment of cortical convolution/gyration pattern in the presence of mild ventriculomegaly indicates the functional organization of the cortex, which may profoundly impact brain function in childhood and adult period. ${ }^{7}$ Fetal MR study provides additional information mainly in those with suspected midline anomalies (i.e., posterior fossa anomalies and agenesis of corpus callosum), which may lead to complete changes of management and parental counseling. Recent systematic review suggested an up to $2.5 \%$ chance of prenatal MR to yield false results. ${ }^{8}$ Maternal diabetes increases the risk of fetal neurocognitive impairment, which may be detected by prenatal MR.9,10

The main acquired fetal brain pathologies detected by MRI are ischemic infarctions and hemorrhage. Ischemic brain infarctions can occur in complicated monochorionic 


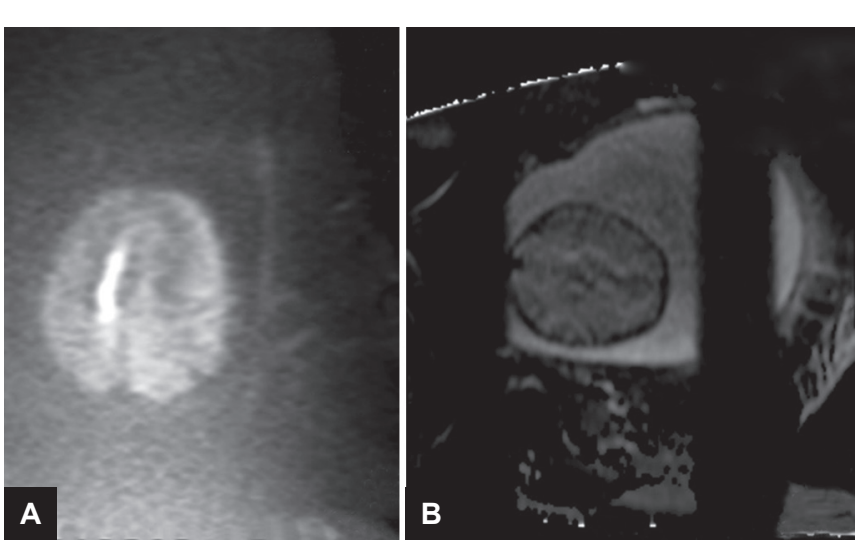

Figs $1 A$ and B: Axial plane of brain of a fetus affected by basal ganglion hemorrhage. The DWI shows bright signal lateral to the ventricle $(A)$. Bright signal on ADC suggests white matter edema $(B)$

twins; early-stage infarction shows restricted MR diffusion. ${ }^{11}$ Subsequently, focal T2-weighted hyperintense lesions and a reduction of brain tissue may develop. ${ }^{12,13}$ Because of changes in local susceptibility caused by blood breakdown products, EPI sequences (i.e., DWI and ADC) are especially sensitive to hemorrhage and edema, as shown in Figure 1. These sequences can also be used to detect calcifications, a consequence of many acquired fetal or maternal diseases. ${ }^{13,14}$ Brain tumors or vascular malformations lead to parenchymal changes; and MR demonstration of these associated findings may direct therapeutic planning. ${ }^{15}$ In addition to morphology study, microstructure, metabolism (spectroscopy), and functional connectivity (tractography) in the fetal brain can be identified. ${ }^{16-18}$ The in utero alterations may explain neurological insults in the childhood and adult periods. ${ }^{19,20}$

\section{Magnetic Resonance Imaging and Fetal Surgery}

Both prenatal ultrasound and MRI can be used to assess severity of congenital diaphragmatic hernia $(\mathrm{CDH}){ }^{21}$ Fetal lung size (or lung-to-head ratio), liver and stomach position, polyhydramnios, gestational age at diagnosis, and cardiac ventricular size, which are predictive of outcome, can be assessed with ultrasound. Lung volume can be estimated using either prenatal three-dimensional ultrasound or MRI, which needs to be offset with the effect of gestational age (observed/expected total fetal lung volume). This estimation may be difficult in the case of uncertain dates or inaccurate when the fetal weight is beyond the normal range, hence, matching can be made on MR fetal body volume. ${ }^{22}$ As lung volumetry is based on several slices through both lungs, and since MRI is not restricted by maternal factors, ultimately, MR volumetry is theoretically more accurate. Magnetic resonance also allows a more scaled quantification of liver "up" or "down", although there is no standardized method for calculating the amount of liver into the thorax. ${ }^{23}$ The fetal lung-to-liver signal intensity ratio on T2-weighted images may be an accurate marker to predict fetal lung maturity. ${ }^{24}$ Postnatal pulmonary hypertension can be accurately predicted with MR prenatal pulmonary hypertension index. ${ }^{25}$ Fetoscopic tracheal occlusion may improve postnatal survival of $\mathrm{CDH}$. The endoluminal occlusion balloon contains a metallic component that may pose MRI-related imaging issues and possible risks for the fetus and mother, such as magnetic field interactions, heating, and artifacts. An in vitro study showed that the balloon displayed minor magnetic field interactions and inconsequential heating. Artifacts extended approximately $10 \mathrm{~mm}$ from the occlusion balloon on the 3-Tesla (3-T) gradient-echo pulse sequence, suggesting that anatomy located at a position greater than this distance may be visualized on MRI. ${ }^{26}$

Fetal MRI has recently been proposed as a complementary approach for the evaluation of lower urinary tract obstruction (LUTO). Two recent studies suggest that additional diagnostic information is gained with MRI in fetuses with LUTO. ${ }^{27,28}$ The DWI sequence may be useful in defining the renal parenchyma by evaluating increased signal intensity on DWI and decreased signal on ADC maps. ${ }^{29}$ However, the case series are small, and further studies are necessary to fully define the benefits of MRI in evaluating and managing patients with LUTO. ${ }^{30}$

Sonographic evaluation of the posterior fossa and the spine is limited by fetal position, maternal body habitus, oligohydramnios, and ossification of the fetal skull. ${ }^{31}$ In most cases, ultrasound and prenatal MRI can both delineate the dysraphic defect and the level of the placode with similar efficacy. ${ }^{32}$ The MRI can allow detailed characterization of the neural tube defect and its associated anomalies, which may be contraindicated to in utero intervention. ${ }^{33,34}$ Strong prognostic factors of open neural tube defects are the level and length of the dysraphic lesion. ${ }^{35}$ Quantifying the degree of cerebellar tonsil herniation is crucial, as worsening herniation has been associated with increased postnatal risk of seizure. Open MRI has been extensively used for studies of fetal surgery for neural tube defects in animal models. ${ }^{36}$

Persistent hyperextension due to fetal neck mass can compromise the airway. Cesarean delivery with ex utero intrapartum treatment to secure the airway is considered or can be considered. ${ }^{37}$ Detailed, high-resolution fetal MRI may serve as a valuable secondary imaging modality for clinical decision-making regarding management of pregnancy, in utero therapy, mode of delivery, and postnatal care. ${ }^{38}$

\section{MR Study of the Placenta and Umbilical Cord}

Ultrasound is highly sensitive and specific in the prenatal "diagnosis" of accreta placentation when performed by 
skilled operators. However, combination of ultrasound signs, such as loss of clear zone, presence of bridging vessels, subplacental hypervascularity, and placental lacunae, is not specific of "grading" the depth of invasive placentation (accreta, increta, or percreta). ${ }^{39}$ Prenatal MRI should be considered as a secondary imaging tool in any case with clinical suspicion for placenta accreta, i.e., placenta previa (especially posterior previa) with previous uterine operation and discordant ultrasound findings, and in any case in which percreta is suspected. ${ }^{3}$ The excellent diagnostic accuracy in identifying the depth, placental villous structure, and the topography of placental invasion came from studies that MRI performed as a secondary imaging tool in women already screened for placenta accreta on ultrasound and might not reflect its actual diagnostic performance in detecting the severity of these disorders. ${ }^{40,41}$

The improved capability of MRI to image placental villous microstructure and the increased precision of oxygen measurement within placental microcirculations allow for a research opportunity to measure placental oxygenation both in vivo and ex vivo. ${ }^{42}$ Simulated crossdisciplinary approaches with mathematical modeling MR sequence data could advance our understanding of oxygen levels within the placentofetal unit, with an emphasis on dysregulated maternofetal oxygen transfer in pregnancy pathologies. ${ }^{43}$ In vivo umbilical vein blood flow rate and fetal oxygenation rate can also be measured noninvasively with quantitative T2 MRI during the second and third trimesters of pregnancy. ${ }^{44}$ Real-time in vivo MR tracking of placental transport for toxic nanomaterials has been studied, so that detoxification of harmful compounds can be implemented. ${ }^{45}$

\section{Safety Concerns of Obstetric MRI}

The 3-T MRI has the potential to provide imaging with higher resolution and better signal-to-noise ratio than does 1.5 Tesla $(1.5 \mathrm{~T})$, while maintaining a comparable or lower energy deposition. The 3-T MRI is superior to 1.5-T MRI; as it (1) Enhances the sensitivity for deoxyhemoglobin and hemosiderin to detect hemorrhagic lesions, (2) enhances the sensitivity for calcifications for sharper delineation of bony structures, (3) enhances the quality of spectroscopy to interrogate for the presence and concentration of various metabolites in fetal tissue, and (4) enhances blood oxygen level-dependent contrast imaging for functional MRI study of fetal brain. ${ }^{46}$ Although there are some theoretical concerns of MR-related heat and acoustic damage to the fetus, recent data from porcine model suggested otherwise. ${ }^{47}$ With appropriate sequence adaptations, 3-T MRI may be used safely during the 2nd and 3rd trimester of pregnancy. ${ }^{6,48,49}$
Without administration of contrast media (Gadolinium), prenatal exposure to MRI is not associated with adverse fetal or long-term neurodevelopmental effects. ${ }^{50,51}$ Gadolinium crosses the placenta, then filtered through fetal kidneys, and can remain in the amniotic fluid for an unknown period of time. Gadolinium-based contrast agents are not widely used in fetal imaging. Experiments in animal models showed that prenatal exposure to gadolinium at high dosage and long duration can cause fetal malformations and growth restriction, but data on the long-term consequences of in utero exposure of gadolinium are more limited. Data of in utero Gadolinium exposure in humans are still limited (Category C). Experimental exposure of gadolinium may be related to mutagenesis and carcinogenesis in postnatal life. Several small case series did not report any adverse neonatal outcomes after first-trimester exposure of gadolinium at clinical dose. This information can be used for counseling the pregnant women who unknowingly underwent MRI examination using gadolinium. ${ }^{52}$

\section{CONCLUSION}

Although fetal MRI is being performed in many perinatal centers, the quality of imaging, sequences used, and operator experience appear to differ widely between centers. ${ }^{53}$ The impact of such differences should be reduced by development of guidelines to define better the role of fetal MRI in relation to prenatal diagnostic ultrasound. The results of MRI examinations increase the positive predictive value of ultrasound alone. The two techniques appear to be complementary and should not be mutually exclusive. The MR quantification of fine and gross movements may advance our understanding of fetal anomalies with challenges in diagnosis. ${ }^{54-56}$ With novel diffusion-tensor MRI and fiber tracking algorithm, quantitative assessment of microarchitecture within the cervix and its ability to resist intrauterine forces associated with pregnancy may broaden the indications of obstetric MRI. ${ }^{57}$

\section{ACKNOWLEDGMENT}

The authors would like to thank Chutima Yaiyiam for her administrative assistance.

\section{REFERENCES}

1. Gagnon A, Genetics C. Evaluation of prenatally diagnosed structural congenital anomalies. J Obstet Gynaecol Can 2009 Sep;31(9):875-881.

2. Platt LD, Barth RA, Pugash D. Current controversies in prenatal diagnosis 3: Fetal MRI should be performed in all prenatally detected fetuses with a major structural abnormality. Prenat Diagn 2018 Feb;38(3):166-172.

3. Wataganara T, Ebrashy A, Aliyu LD, Moreira de Sa RA, Pooh R, Kurjak A, Sen C, Adra A, Stanojevic M. Fetal magnetic 
resonance imaging and ultrasound. J Perinat Med 2016 Jul 1;44(5):533-542.

4. Dietrich O, Geith T, Reiser MF, Baur-Melnyk A. Diffusion imaging of the vertebral bone marrow. NMR Biomed 2017 Mar;30(3).

5. Wataganara T. Foetal magnetic resonance imaging. In: Studd J, Tan S, Chervenak F, eds. Current progress in obstetrics \& gynecology, Vol. 4. Maharashtra: Tree Life Media; 2017. pp. 168-191.

6. Prayer D, Malinger G, Brugger PC, Cassady C, De Catte L, De Keersmaecker B, Fernandes GL, Glanc P, Gonçalves LF, Gruber GM, et al. ISUOG Practice Guidelines: performance of fetal magnetic resonance imaging. Ultrasound Obstet Gynecol 2017 May;49(5):671-680

7. Benkarim OM, Hahner N, Piella G, Gratacos E, González Ballester MA, Eixarch E, Sanroma G. Cortical folding alterations in fetuses with isolated non-severe ventriculomegaly. Neuroimage Clin 2018 Jan 28;18:103-114.

8. Rossi AC, Prefumo F. Additional value of fetal magnetic resonance imaging in the prenatal diagnosis of central nervous system anomalies: a systematic review of the literature. Ultrasound Obstet Gynecol 2014 Oct;44(4):388-393.

9. Denison FC, Macnaught G, Semple SIK, Terris G, Walker J, Anblagan D, Serag A, Reynolds RM, Boardman JP. Brain development in fetuses of mothers with diabetes: a casecontrol MR imaging study. AJNR Am J Neuroradiol 2017 May;38(5):1037-1044.

10. Wataganara T. Fetal malformations detected with magnetic resonance imaging in diabetic mother. In: Hod M, Jovanovic L, Di Renzo G, De Leiva A, Langer O, eds. Textbook of diabetes and pregnancy. 3rd ed. Boca Raton: Taylor \& Francis Group; 2016. pp. 351-361.

11. Weisz B, Hoffmann C, Ben-Baruch S, Yinon Y, Gindes L, Katorza E, Shrim A, Bar Yosef O, Schiff E, Lipitz S. Early detection by diffusion-weighted sequence magnetic resonance imaging of severe brain lesions after fetoscopic laser coagulation for twin-twin transfusion syndrome. Ultrasound Obstet Gynecol 2014 Jul;44(1):44-49.

12. Garel C, Delezoide AL, Elmaleh-Berges M, Menez F, FalletBianco C, Vuillard E, Luton D, Oury JF, Sebag G. Contribution of fetal MR imaging in the evaluation of cerebral ischemic lesions. AJNR Am J Neuroradiol 2004 Oct;25(9):1563-1568.

13. Prayer D, Brugger PC, Kasprian G, Witzani L, Helmer H, Dietrich W, Eppel W, Langer M. MRI of fetal acquired brain lesions. Eur J Radiol 2006 Feb;57(2):233-249.

14. Benoist G, Salomon LJ, Mohlo M, Suarez B, Jacquemard F, Ville Y. Cytomegalovirus-related fetal brain lesions: comparison between targeted ultrasound examination and magnetic resonance imaging. Ultrasound Obstet Gynecol 2008 Dec;32(7):900-905.

15. Brunelle F. Brain vascular malformations in the fetus: diagnosis and prognosis. Childs Nerv Syst 2003 Aug;19(7-8):524-528.

16. Pugash D, Krssak M, Kulemann V, Prayer D. Magnetic resonance spectroscopy of the fetal brain. Prenat Diagn 2009 Apr;29(4):434-441.

17. Yoshida S, Oishi K, Faria AV, Mori S. Diffusion tensor imaging of normal brain development. Pediatr Radiol 2013 Jan;43(1):15-27.

18. Mitter C, Jakab A, Brugger PC, Ricken G, Gruber GM, Bettelheim D, Scharrer A, Langs G, Hainfellner JA, Prayer D, et al. Validation of in utero tractography of human fetal commissural and internal capsule fibers with histological structure tensor analysis. Front Neuroanat 2015 Dec 24;9:164.
19. Brossard-Racine M, Limperopoulos C. Normal cerebellar development by qualitative and quantitative $\mathrm{mr}$ imaging: from the fetus to the adolescent. Neuroimaging Clin N Am 2016 Aug;26(3):331-339.

20. Thomason ME, Scheinost D, Manning JH, Grove LE, Hect J, Marshall N, Hernandez-Andrade E, Berman S, Pappas A, Yeo L, et al. Weak functional connectivity in the human fetal brain prior to preterm birth. Sci Rep 2017 Jan 9;7:39286.

21. Benachi A, Cordier AG, Cannie M, Jani J. Advances in prenatal diagnosis of congenital diaphragmatic hernia. Semin Fetal Neonatal Med 2014 Dec;19(6):331-337.

22. Nawapun K, Sandaite I, Dekoninck P, Claus F, Richter J, De Catte L, Deprest J. Comparison of matching by body volume or gestational age for calculation of observed to expected total lung volume in fetuses with isolated congenital diaphragmatic hernia. Ultrasound Obstet Gynecol 2014 Dec;44(6):655-660.

23. Cannie MM, Cordier AG, De Laveaucoupet J, Franchi-Abella S, Cagneaux M, ProdhommeO, Senat MV, Mokhtari M, Vlieghe V, Nowakowska D, et al. Liver-to-thoracic volume ratio: use at MR imaging to predict postnatal survival in fetuses with isolated congenital diaphragmatic hernia with or without prenatal tracheal occlusion. Eur Radiol 2013 May;23(5): 1299-1305.

24. Oka Y, Rahman M, Sasakura C, Waseda T, Watanabe Y, Fujii R, Makinoda S. Prenatal diagnosis of fetal respiratory function: evaluation of fetal lung maturity using lung-to-liver signal intensity ratio at magnetic resonance imaging. Prenat Diagn 2014 Dec;34(13):1289-1294.

25. Vuletin JF, Lim FY, Cnota J, Kline-Fath B, Salisbury S, Haberman B, Kingma P, Frischer J, Crombleholme T. Prenatal pulmonary hypertension index: novel prenatal predictor of severe postnatal pulmonary artery hypertension in antenatally diagnosed congenital diaphragmatic hernia. J Pediatr Surg 2010 Apr;45(4):703-708.

26. Victoria T, Johnson AM, Adzick NS, Hedrick HL, Shellock FG Evaluation of magnetic resonance imaging safety and imaging issues associated with the occlusion balloon used during fetoscopic endoluminal tracheal occlusion. Fetal Diagn Ther 2017 Oct 5.

27. Pico H, Dabadie A, Bourliere-Najean B, Philip N, Capelle M, Aschero A, Quarello E, Guys JM, Hery G, Petit P, et al. Contribution of the foetal uro-MRI in the prenatal diagnosis of uronephropathies. Diagn Interv Imaging 2014 Jun;95(6):573-578.

28. Alamo L, Laswad T, Schnyder P, Meuli R, Vial Y, Osterheld MC, Gudinchet F. Fetal MRI as complement to US in the diagnosis and characterization of anomalies of the genito-urinary tract. Eur J Radiol 2010 Nov;76(2):258-264.

29. Faure A, Panait N, Panuel M, Alessandrini P, D'Ercole C, Chaumoitre K, Merrot T. Predicting postnatal renal function of prenatally detected posterior urethral valves using fetal diffusion-weighted magnetic resonance imaging with apparent diffusion coefficient determination. Prenat Diagn 2017 Jul;37(7):666-672.

30. Savelli S, Di Maurizio M, Perrone A, Tesei J, Francioso A, Angeletti M, La Barbera L, Ballesio L, de Felice C, Porfiri LM, et al. MRI with diffusion-weighted imaging (DWI) and apparent diffusion coefficient (ADC) assessment in the evaluation of normal and abnormal fetal kidneys: preliminary experience. Prenat Diagn 2007 Dec;27(12):1104-1111.

31. Bulas D. Fetal evaluation of spine dysraphism. Pediatr Radiol 2010 Jun;40(6):1029-1037. 
32. Aaronson OS, Hernanz-Schulman M, Bruner JP, Reed GW, Tulipan NB. Myelomeningocele: prenatal evaluationcomparison between transabdominal US and MR imaging. Radiology 2003 Jun;227(3):839-843.

33. Danzer E, Johnson MP. Fetal surgery for neural tube defects. Semin Fetal Neonatal Med 2014 Feb;19(1):2-8.

34. Adzick NS, Thom EA, Spong CY, Brock JW 3rd, Burrows PK, Johnson MP, Howell LJ, Farrell JA, Dabrowiak ME, Sutton LN, et al. A randomized trial of prenatal versus postnatal repair of myelomeningocele. N Engl J Med 2011 Mar 17;364(11):993-1004.

35. Chao TT, Dashe JS, Adams RC, Keefover-Hicks A, McIntire DD, Twickler DM. Fetal spine findings on MRI and associated outcomes in children with open neural tube defects. AJR Am J Roentgenol 2011 Nov;197(5):W956-W961.

36. Watanabe M, Li H, Kim AG, Weilerstein A, Radu A, Davey M, Loukogeorgakis S, Sánchez MD, Sumita K, Morimoto N, et al. Complete tissue coverage achieved by scaffold-based tissue engineering in the fetal sheep model of Myelomeningocele. Biomaterials 2016 Jan;76:133-143.

37. Wataganara T, Ngerncham S, Kitsommart R, Fuangtharnthip P. Fetal neck myofibroma. J Med Assoc Thai 2007 Feb;90(2): 376-380.

38. Shrot S, Johnson CT, Golden WC, Baschat AA, Bullard JE, Tekes A, Poretti A, Dunn E, Huisman TAGM. Persistent extreme hyperextension of the fetal neck: clinical and neuroimaging findings. J Neuroimaging 2018 May;28(3):278-282.

39. Jauniaux E, Bhide A. Prenatal ultrasound diagnosis and outcome of placenta previa accreta after cesarean delivery: a systematic review and meta-analysis. Am J Obstet Gynecol 2017 Jul;217(1):27-36.

40. Familiari A, Liberati M, Lim P, Pagani G, Cali G, Buca D, Manzoli L, Flacco ME, Scambia G, D'antonio F. Diagnostic accuracy of magnetic resonance imaging in detecting the severity of abnormal invasive placenta: a systematic review and meta-analysis. Acta Obstet Gynecol Scand 2018 May;97(5):507-520.

41. Valentini AL, Gui B, Ninivaggi V, Miccò M, Giuliani M, Russo L, Marini MG, Tintoni M, Cavaliere AF, Bonomo L. The morbidly adherent placenta: when and what association of signs can improve MRI diagnosis? Our experience. Diagn Interv Radiol 2017 May-Jun;23(3):180-186.

42. Slator PJ, Hutter J, McCabe L, Gomes AD, Price AN, Panagiotaki E, Rutherford MA, Hajnal JV, Alexander DC. Placenta microstructure and microcirculation imaging with diffusion MRI. Magn Reson Med 2018 Aug;80(2):756-766.

43. Nye GA, Ingram E, Johnstone ED, Jensen OE, Schneider $H$, Lewis RM, Chernyavsky IL, Brownbill P. Human placental oxygenation in late gestation: experimental and theoretical approaches. J Physiol 2018 Jan 26.

44. Rodriguez-Soto AE, Langham MC,AbdulmalikO, Englund EK, Schwartz N, Wehrli FW. MRI quantification of human fetal O2 delivery rate in the second and third trimesters of pregnancy. Magn Reson Med 2018 Sep;80(3):1148-1157.

45. Sweeney S, Adamcakova-Dodd A, Thorne PS, Assouline JG. Multifunctional nanoparticles for real-time evaluation of toxicity during fetal development. PLoS One 2018 Feb 8;13(2): e0192474.

46. Weisstanner C, Gruber GM, Brugger PC, Mitter C, Diogo MC, Kasprian G, Prayer D. Fetal MRI at 3T-ready for routine use? Br J Radiol 2017 Jan;90(1069):20160362.

47. Cannie MM, De Keyzer F, Van Laere S, Leus A, de Mey J, Fourneau C, De Ridder F, Van Cauteren T, Willekens I, Jani JC. Potential heating effect in the gravid uterus by using 3-T MR imaging protocols: experimental study in miniature pigs. Radiology 2016 Jun;279(3):754-761.

48. Patenaude Y, Pugash D, Lim K, Morin L, Lim K, Bly S, Butt K, Cargill Y, Davies G, Denis N, et al. The use of magnetic resonance imaging in the obstetric patient. J Obstet Gynaecol Can 2014 Apr;36(4):349-363.

49. Barth R, Victoria T, Kline-Fath B, Estroff J, Society for Pediatric Radiology Fetal Imaging Committee. ISUOG Guidelines for fetal MRI: a response to 3-T fetal imaging and limited fetal exams. Ultrasound Obstet Gynecol 2017 Dec;50(6):804-805.

50. Ray JG, Vermeulen MJ, Bharatha A, Montanera WJ, Park AL. Association between MRI exposure during pregnancy and fetal and childhood outcomes. JAMA 2016 Sep 6;316(9):952-961.

51. Bouyssi-KobarM, duPlessisAJ, Robertson RL, LimperopoulosC. Fetal magnetic resonance imaging: exposure times and functional outcomes at preschool age. Pediatr Radiol 2015 Nov;45(12):1823-1830.

52. Committee on Obstetric Practice. Committee Opinion No. 723: Guidelines for diagnostic imaging during pregnancy and lactation. Obstet Gynecol 2017 Oct;130(4):e210-e216.

53. Malinger G, Lev D, Lerman-Sagie T. Is fetal magnetic resonance imaging superior to neurosonography for detection of brain anomalies? Ultrasound Obstet Gynecol 2002 Oct;20(4):317-321.

54. Salomon LJ, Sonigo P, Ou P, Ville Y, Brunelle F. Real-time fetal magnetic resonance imaging for the dynamic visualization of the pouch in esophageal atresia. Ultrasound Obstet Gynecol 2009 Oct;34(4):471-474.

55. Hochart V, Verpillat P, Langlois C, Garabedian C, Bigot J, Debarge VH, Sfeir R, Avni FE. The contribution of fetal MR imaging to the assessment of oesophageal atresia. Eur Radiol 2015 Feb;25(2):306-314.

56. Verbruggen SW, Kainz B, Shelmerdine SC, Hajnal JV, Rutherford MA, Arthurs OJ, Phillips AT, Nowlan NC. Stresses and strains on the human fetal skeleton during development. J R Soc Interface 2018 Jan;15(138):20170593.

57. Nott JP, Pervolaraki E, Benson AP, Bonney EA, Pickering JD, Wilkinson N, Simpson N. Diffusion tensor imaging determines three-dimensional architecture of human cervix: a cross-sectional study. BJOG 2018 Jun;125(7):812-818. 